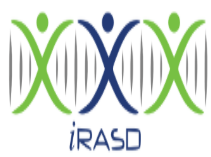

iRASD Journal of Management

Volume 3, Number 3, 2021, Pages 310 - 317

\title{
Knowledge Sharing and Competitive Advantage in Public Universities: Mediating Role of Strategic Intent
}

\author{
Kashif Akram ${ }^{1}$, Usman Ahmad² \\ ${ }^{1}$ Department of Management and HRM, IBMAS, The Islamia University of Bahawalpur, Bahawalpur. \\ Email kashif.akram@iub.edu.pk \\ ${ }^{2}$ DHA Suffa University, Karachi, Pakistan. Email: usmanahmadjee87@gmail.com
}

\begin{tabular}{|c|c|}
\hline \multicolumn{2}{|c|}{ ARTICLE INFO } \\
\hline $\begin{array}{l}\text { Article History: } \\
\text { Received: } \\
\text { Revised: } \\
\text { Accepted: } \\
\text { Available Online: }\end{array}$ & $\begin{array}{l}\text { November 28, } 2021 \\
\text { December 28, } 2021 \\
\text { December 28, } 2021 \\
\text { December 30, } 2021\end{array}$ \\
\hline $\begin{array}{l}\text { Keywords: } \\
\text { Competitive adva } \\
\text { Knowledge shari } \\
\text { Strategic intent } \\
\text { Pakistan }\end{array}$ & $\begin{array}{l}\text { antage } \\
\text { ng }\end{array}$ \\
\hline
\end{tabular}

\begin{abstract}
Public universities are the major source of higher education all over the world. Therefore, competitive public universities play a significant role in producing an effective labour force for society. The basic objective of the study is to examine the mediating role of strategic intent on the relationship between knowledge sharing and competitive advantage in the public higher education institutions (PHEIs) of Pakistan. Data were collected from the top management of the PHEIs of Pakistan by distributing the structured close-ended questionnaire. A total number of 192 questionnaires were received in a fully completed form that has been used for the final analysis. PLSSEM was employed to examine measurement and structural model of the path model. The results reveal that $\mathrm{KS}$ is significantly and positively related to strategic intent and CA. Strategic intent also found to be significantly and positively related to $\mathrm{CA}$. In addition, strategic intent mediates the relationship between $\mathrm{KS}$ and $\mathrm{CA}$.
\end{abstract} article under the Creative Common Attribution Non-Commercial 4.0

Corresponding Author's Email: kashif.akram@iub.edu.pk

\section{Introduction}

Education is a soul for any civilized society for developing intellectuals, unique thinkers and changing attitudes and behaviors of the masses that uplift the overall society in terms of economy, values and culture. Therefore, Higher Education Institutions (HEIs) play a critical role in producing lawyers, doctors, engineers, philosophers and scientists besides a group of another workforce (Trow, 2005). HEIs are also considered knowledgeintensive organisations (Howell \& Annansingh, 2013), knowledge-creating institutions, and knowledge business (Rowley, 2000). However, developing countries are lagging far behind in building knowledge-based institutions (UNESCO, 2004). Therefore, developing countries had failed to compete with developed countries globally due to the incompetitiveness of their knowledge-based institutions/universities (Ramoniene \& Lanskoronskis, 2011). The prior literature discussed competitive advantage (CA) in the context of higher education (i.e (Cheung \& Chan, 2010; H. De Haan, 2014; H. H. De Haan, 2015). However, most of the studies were qualitative and unable to quantify CA in the context of PHEIs. Moreover, previous studies also found knowledge management crucial to attain CA (Jyoti, Kotwal, \& Rani, 2015; Wu \& Chen, 2012), especially knowledge sharing (Arsawan et al., 2020; Eidizadeh, Salehzadeh, \& Esfahani, 2017; Magnier-Watanabe \& Senoo, 2009; Reid, 2003). Nevertheless, few studies that utilized strategic intent between knowledge sharing (KS) and $\mathrm{CA}$ as strategic intent have been identified as an important construct to attain CA in a highly volatile environment (Seepana, Paulraj, \& Huq, 2020). Thus, this study aims to examine the mediating role of strategic intent between KS and CA in PHEIs of Pakistan. 


\section{Literature Review and Hypothesis Development 2.1. Knowledge Sharing and Competitive Advantage}

Knowledge sharing is a social interaction where employees meet and share their experiences, knowledge and skills that enhance their overall efficiency and effectiveness. Similarly, Hoopes and Postrel (1999) also asserted that knowledge sharing in organisations is viewed as a social process through which different functions and organisation members share their experiences and information that has a synergy impact on organisation members' performance. Knowledge sharing provides an opportunity to meet those needs and preferences that enhances CA (Reid, 2003). Knowledge sharing is a critical and valuable factor that plays its role in attaining CA (Lin \& Chen, 2008) through better organisation routines and processes (Huber, 1996). Moreover, Deshpandé, Farley, and Webster Jr (1993) concluded that the unique product development process depends on the knowledge sharing of customers that essentially provides CA (Akroush, 2012). Since knowledge sharing and strong collaboration among internal organisation employees and external organisation partners is vital (Dutta, Narasimhan, \& Rajiv, 1999), the knowledge of suppliers' capabilities and customer insights is critical for timely and cost-effective decisionmaking (Naylor et al., 1993). Therefore, the first hypothesis is developed below:

H1: Knowledge sharing significantly and positively related to $C A$

\subsection{Knowledge Sharing and Strategic Intent}

Knowledge sharing is crucial for firms to glean knowledge from external sources, and it is also beneficial for the organization while determining the strategic intent (Devarakonda \& Reuer, 2018; Simonin, 2004). Knowledge encompasses several components like products and services, planning, competitive intelligence for knowledge acquisition (Devarakonda \& Reuer, 2018). Knowledge sharing affects organizations strategic intent as it gives information and knowledge about strategic partners' skills, abilities and competence, which would not have been possible without indulging in partnership (Lei, 1993). Therefore, knowledge sharing is imperative for organizations for strategic intent as it adds value for the organization both while in competition or cooperation (Bouncken \& Fredrich, 2016; Soekijad \& Andriessen, 2003). Hence, the following hypothesis may be drawn:

H2: Knowledge sharing is significantly and positively related to strategic intent

\subsection{Strategic Intent and Competitive Advantage}

Strategic intent categorically states the organization's purpose and strategic position (Johnson \& Sohi, 2001), which effectively communicate and share with all stakeholders (O'Shannassy, 2016), which develops internal and external stakeholders' confidence in the organisation. Organisational strategic intent would share ambition and source of CA in fierce competition. Strategic intent helps develop dynamic capabilities which keep on creating and updating organizational resources and capabilities (Døving \& Gooderham, 2008) that gains CA for the organization (Akram, Hilman, \& Ahmad, 2018). Whereas (O'Shannassy, 2016). Argued that strategic intent also does the same for organizations as in the case of dynamic capabilities; therefore, both are two sides of one coin and the source of CA. Thus, a third hypothesis is generated:

H3: strategic intent is significantly and positively related to $C A$

\subsection{Strategic Intent as A Mediator Between KS And CA}

In today's dynamic environment, strategic intent has become a crucial element to win a market share and outperform the competitors. It serves in identifying the business objectives and strategic direction of any organization. It also guides how an organization can generate resources and choose better objectives (O'Reilly III \& Tushman, 2011) to attain CA. The strategic intent of any organization largely depends on how an organization interacts and share knowledge of external forces in terms of technology, culture and consumer's taste and preferences. Therefore, greater knowledge sharing better will be the 
strategic intent as it enhances the core competencies and employee capabilities within the organization (Koza \& Lewin, 2000), consequently leading towards CA. Thereby, the fourth hypothesis is developed below:

H4: Strategic intent mediates the relationship between KS and CA

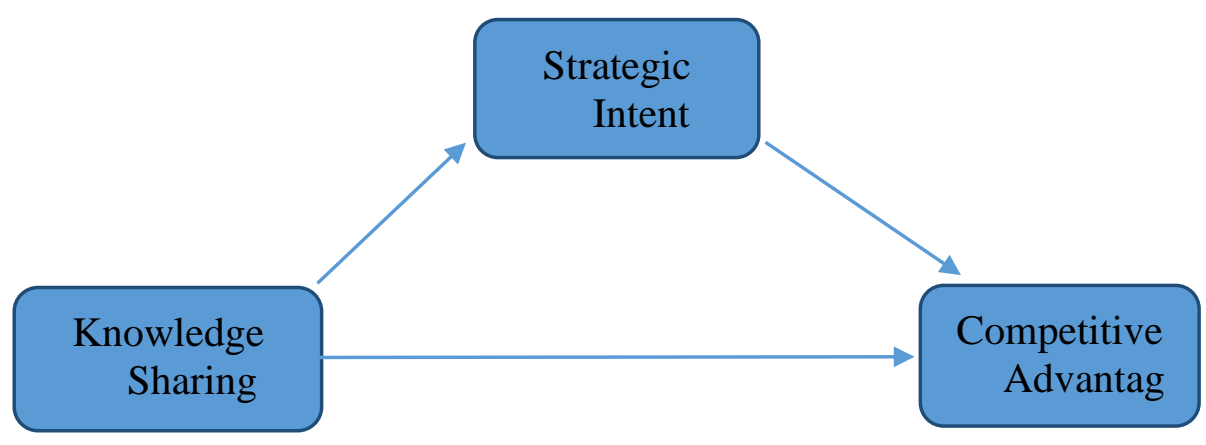

Figure 1: Conceptual Framework

\section{Methodology}

The basic objective of the current study is to examine the mediating role of strategic intent on the relationship between knowledge sharing and competitive advantage in PHEIs of Pakistan. The data were collected from the top leadership of PHEIs of Pakistan, including Deans, Professors and registrars, as they are the key personnel to take the strategic decision of PHEIs and craft strategic intent. The list of the key personnel of each university was developed by visiting the website of each PHEI. The structured close-ended questionnaire was distributed by employing a proportionate stratified sampling technique. A total of 192 valid questionnaires were received in a filled form thus, considered for the final analysis. PLS-SEM technique was employed to analyze the data and for hypothesis testing. There are various reasons to utilize the PLS-SEM for the data analysis. Firstly, normality is one of the primary data collection issues that inflates or deflates the results; PLS-SEM provides good results on non-normal data (Hair, Risher, Sarstedt, \& Ringle, 2019). Secondly, PLS-SEM provides accurate results even though the path model is complex (Hair Jr, Hult, Ringle, \& Sarstedt, 2021).

\subsection{Measurements}

All scales of the current study are derived from the previous studies to ensure content validity. The measurement of knowledge acquisition adapted from Andreeva and Kianto (2011) comprising six items. In addition, the measurement of strategic intent is derived from the work of Seepana et al. (2020), containing four items. Furthermore, this research adapted seven items scale of CA from the work of Chen and Chang (2013) and three items from the previous literature e.g. (H. H. De Haan, 2015) that fit in the context of the study. The reliability coefficient of CA reported in this study is 0.8 and fits in the context of the current study. All items were measured on 5 points Likert scale ranging from 1 to 5 , where 1 denoted strongly disagree and 5 denoted strongly agree.

\section{Result and Interpretation 4.1. Measurement Model}

The current study adopted the two-stage model, including measurement and structural model, utilised by prominent researchers in PLS-SEM such as Hair Jr and Lukas (2014) and Wetzels, Odekerken-Schröder, and Van Oppen (2009). Therefore, prior to hypothesis testing, ensuring a measurement model is mandatory as recommended by (Hair et al., 2019). To ensure the measurement model, several criteria need to be considered, such as factor loadings, composite reliability (CR) and average variance extract (AVE), as suggested by (Hair et al., 2019). Furthermore, Hair Jr and Lukas (2014) indicated two criteria regarding factor loadings of the construct: (i) at a minimum, all factor loadings of the construct items should be significant; ii) all factor loadings should meet the threshold value of 0.70 . Moreover, items with factor loadings lower than 0.70 must be deleted. Another criterion mentioned above to ensure convergent validity is composite reliability 
(CR). It shows that all values of CR of all constructs of the current study meet the threshold value of 0.70 as recommended by Hair et al. (2019). Table 1 depicts that after deletion of items showing factor loadings less than 0.70 , remaining factor loadings and CR of respective constructs are greater than 0.70 , thus establishing inter-item reliability and overall construct reliability used in the current study. The final standard to measure the measurement model is AVE.

Table 1

Measurement Model

\begin{tabular}{lllll}
\hline Constructs & Items & $\begin{array}{c}\text { Factor } \\
\text { Loadings }\end{array}$ & CR & AVE \\
\hline Competitive & CA4 & 0.882 & & \\
Advantage & CA5 & 0.774 & 0.921 & 0.700 \\
& CA6 & 0.866 & & \\
& CA7 & 0.815 & 0.862 & 0.758 \\
Knowledge & CA8 & 0.843 & & \\
Sharing & KS1 & 0.825 & 0.772 \\
Strategic Intent & KS2 & 0.914 & & \\
& SI1 & 0.867 & & \\
& SI2 & 0.901 & & \\
& SI3 & 0.913 & & \\
& SI4 & 0.832 & & \\
\hline
\end{tabular}

Table 1 shows that all values of AVE exceed the recommended value of 0.50 (Hair Jr \& Lukas, 2014), which shows that the average variance extracted from the set of items in relation to the variance shared is greater than the measurement errors. It indicates the adequate convergent validity of the construct.

\subsubsection{Discriminant Validity}

The outer model's construct validity also requires the validation of discriminant validity. This is a mandatory stage before testing the hypothesis. Hair Jr et al. (2021) define it as "the extent to which a construct is truly distinct from another construct by empirical standards". The Fornell-Larcker criterion was presented by Fornell and Larcker (1981). The square root of AVE of all constructs placed at the correlation matrix of diagonal elements are presented in table 2 , which shows that AVE of a diagonal construct has a greater value than other constructs presented in the rows. Thus, it ensures the discriminant validity of all latent constructs of this study.

Table 2

Discriminant Validity

\begin{tabular}{llll}
\hline & CA & KS & SI \\
\hline CA & 0.837 & & \\
KS & 0.499 & 0.871 & 0.879 \\
SI & 0.613 & 0.584 & \\
\hline
\end{tabular}

\subsection{Structural Model}

After determining the goodness of the outer model, it is now possible to carry out the hypotheses testing. Hypotheses testing is done by using the Smart PLS version (3.2.7). To determine the significance of the current research hypothesis, path coefficients were tested through the bootstrapping technique as recommended by Hair et al. (2019).

Figure 2 shows the direct path and mediation analysis of the structural model. The significance of the direct path and mediation was confirmed through t-values and $\mathrm{p}$-values of each hypothesis, as shown in Table 3. 


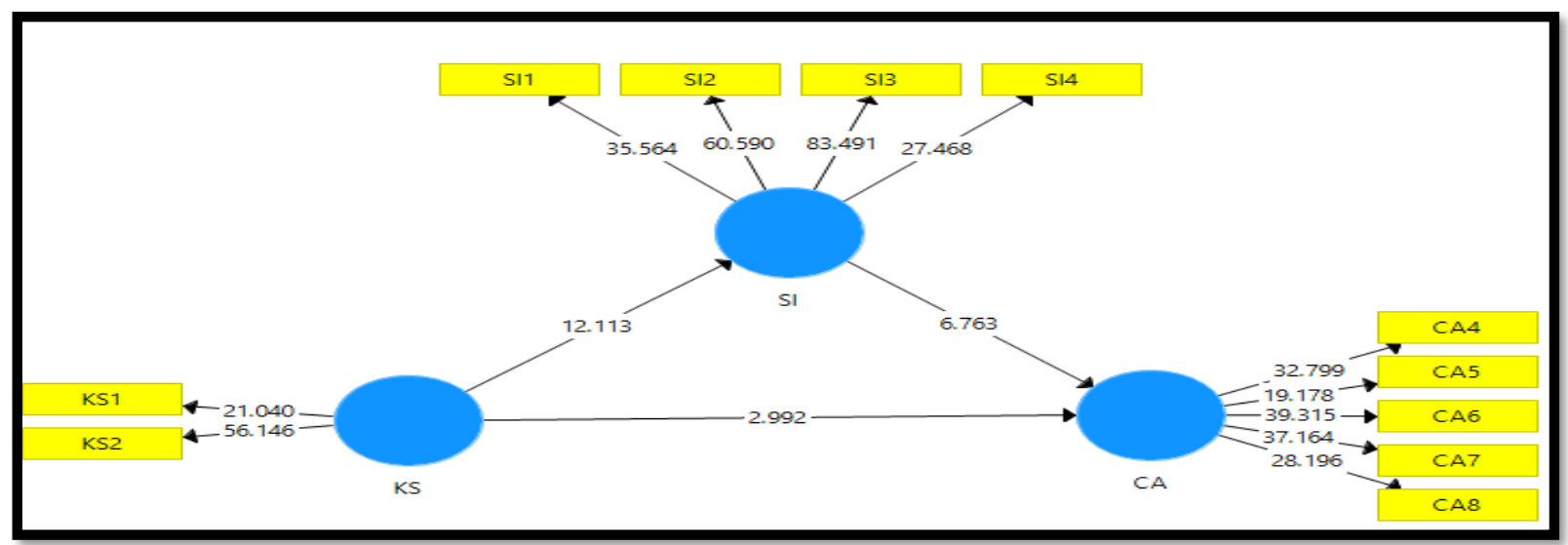

Figure 2: Direct Path and Mediation Analysis

Table 3

Structural Model

\begin{tabular}{ccccc}
\hline & B & $\begin{array}{c}\text { Standard } \\
\text { Deviation }\end{array}$ & T Statistics & P Values \\
\hline KS -> CA & 0.214 & 0.072 & 2.992 & 0.003 \\
KS - SI & 0.584 & 0.048 & 12.113 & 0.000 \\
SI - > CA & 0.488 & 0.072 & 6.763 & 0.000 \\
KS $>$ SI - > CA & 0.285 & 0.044 & 6.477 & 0.000 \\
\hline
\end{tabular}

Table 3 reveals the direct hypothesis results of the current study. It shows that $\mathrm{KS}$ is significantly and positively related to CA in PHEIs of Pakistan $(\beta=0.214 t=2.99, P<0.01)$. This result does support H1. Thus, the current study accepts $\mathrm{H} 1$. Moreover, KS is also significantly and positively related to strategic intent PHEIs of Pakistan $(\beta=0.584, t=12.11$, $\mathrm{P}<0.001$ ), and it supports $\mathrm{H} 2$, therefore making $\mathrm{H} 2$ acceptable. In addition to this, strategic intent also shows a significant and positive relationship with CA in PHEIs of Pakistan $(\beta=0.488, t=6.763, P<0.01)$. It reveals that $H 3$ is supported; thus, $H 3$ is accepted. Figure 3 also presents the mediating role of strategic intent on the relationship between KS and CA. It was hypothesised that strategic intent mediates the relationship between KS and CA in PHEIs of Pakistan. Based on Table 3, the Indirect path is significant $(\beta=0.285, t=6.477$, $\mathrm{P}<0.001)$. This result indicates that strategic intent mediates the relationship between $\mathrm{KS}$ and CA in PHEIs of Pakistan. Therefore, $\mathrm{H} 4$ is supported; hence it is accepted.

\section{Discussion}

This research aims to empirically examine the mediating role of strategic intent on the relationship between KS and CA in the PHEIs of Pakistan. The first hypothesis examined the relationship between $\mathrm{KS}$ and $\mathrm{CA}$, which was found to be positive and significant. It is in line with the various previous studies such as (Hoopes \& Postrel, 1999; Lin \& Chen, 2008; Reid, 2003) and (Huber, 1996). Moreover, the second hypothesis was aimed to examine the relationship between $\mathrm{KS}$ and strategic intent. The result reveals that KS is positively and significantly related to strategic intent. This result is also in accord with the prior literature, for instance (Bouncken \& Fredrich, 2016; Devarakonda \& Reuer, 2018; Soekijad \& Andriessen, 2003) that supports the argument that KS is an important predictor of strategic intent in the organizations. Furthermore, a third hypothesis was generated to examine whether strategic intent is positively and significantly related to CA. Results show the positive and significant relationship between strategic intent and CA, which also validates the previous studies' results such as (Døving \& Gooderham, 2008; O'Reilly III \& Tushman, 2011; O'Shannassy, 2016). The fourth and final hypothesis reveals that strategic intent also mediated the relationship between KS and CA in PHEIs of Pakistan. All four hypotheses have been accepted based on empirical data and output.

\section{Managerial Implication}

This study presents some crucial implications for the top leadership of PHEIs of Pakistan to attain CA in this cutthroat competition. Firstly, industry and society are considered the most important partners of any university. Therefore, top management should emphasize developing strong ties with their partners in the industry and society to 
provide clarity about strategic intent. The strong ties with industry and society may contribute to gleaning knowledge about students' ever-changing demands. This may lead to the development of unique courses, programs, and syllabus to make universities different and better than competitors, both public and private HEIs. Furthermore, the deeply rooted values of KS also underpin the organization's strategic intent where they decide and differentiate themselves from competitors in the same industry. The findings also guide the top management of PHEIs that KS activities should have aimed to craft strategic intent to help attain CA. KS activities at PHEIs should be multifaceted and multi-sources to make shared knowledge richer and more insightful.

\section{Conclusion}

Public higher education institutions are the major source of education in developing countries. Therefore, attaining a competitive advantage for these institutions are pivotal. The current study examines the mediating role of strategic intent between knowledge sharing and competitive advantage. This study's findings reveal some interesting facts based on the empirical data where KS and strategic intent are important predictors of CA. Furthermore, the hypothesized path of KS, strategic intent and CA is also significant in the context of PHEIs, which is fruitful for the understanding and policymaking for top management of PHEIs.

\subsection{Recommendation}

This study made various recommendations based on the results drawn from the empirical data. Firstly, PHEIs should understand the importance of CA as it would provide ways of making their programs, courses and syllabus different and better compared to local and global competitors. Secondly, the PHEIs should create and promote a KS culture to expedite knowledge expansion within the 315 organization. Thirdly, PHEIs should focus on creating a mechanism that supports KS to craft strategic intent containing clear ambitions and strategic position in the education industry.

\section{References}

Akram, K., Hilman, H., \& Ahmad, U. (2018). Factors affecting Competitive Advantage of Public Higher Education Institutions of Pakistan. Strategic Alliance Between AGBA, Millikin University (USA), IIM-Rohtak (India) and Gift Society (India), 364.

Akroush, M. N. (2012). Organizational capabilities and new product performance: The role of new product competitive advantage. Competitiveness Review: An International Business Journal, 22(4), 343-365. doi:https://doi.org/10.1108/10595421211247178

Andreeva, T., \& Kianto, A. (2011). Knowledge processes, knowledge-intensity and innovation: a moderated mediation analysis. Journal of knowledge management, 15(6), 1016-1034. doi:https://doi.org/10.1108/13673271111179343

Arsawan, I. W. E., Koval, V., Rajiani, I., Rustiarini, N. W., Supartha, W. G., \& Suryantini, N. P. S. (2020). Leveraging knowledge sharing and innovation culture into SMEs sustainable competitive advantage. International Journal of Productivity and Performance Management. doi:https://doi.org/10.1108/IJPPM-04-2020-0192

Bouncken, R. B., \& Fredrich, V. (2016). Learning in coopetition: Alliance orientation, network size, and firm types. Journal of Business Research, 69(5), 1753-1758. doi:https://doi.org/10.1016/j.jbusres.2015.10.050

Chen, Y.-S., \& Chang, K.-C. (2013). The nonlinear effect of green innovation on the corporate competitive advantage. Quality \& Quantity, 47(1), 271-286. doi:https://doi.org/10.1007/s11135-011-9518-x

Cheung, H. Y., \& Chan, A. W. H. (2010). Education and competitive economy: how do cultural dimensions fit in? Higher Education, 59(5), 525-541. doi:https://doi.org/10.1007/s10734-009-9263-4

De Haan, H. (2014). Can internationalisation really lead to institutional competitive advantage?-a study of 16 Dutch public higher education institutions. European Journal of Higher Education, 4(2), 135-152. doi:https://doi.org/10.1080/21568235.2013.860359 
De Haan, H. H. (2015). Competitive advantage, what does it really mean in the context of public higher education institutions? International Journal of Educational Management, 29(1), 44-61. doi:https://doi.org/10.1108/IJEM-07-2013-0115

Deshpandé, R., Farley, J. U., \& Webster Jr, F. E. (1993). Corporate culture, customer orientation, and innovativeness in Japanese firms: a quadrad analysis. Journal of marketing, 57(1), 23-37. doi:https://doi.org/10.1177/002224299305700102

Devarakonda, S. V., \& Reuer, J. J. (2018). Knowledge sharing and safeguarding in R\&D collaborations: The role of steering committees in biotechnology alliances. Strategic Management Journal, 39(7), 1912-1934. doi:https://doi.org/10.1002/smj. 2898

Døving, E., \& Gooderham, P. N. (2008). Dynamic capabilities as antecedents of the scope of related diversification: the case of small firm accountancy practices. Strategic Management Journal, 29(8), 841-857. doi:https://doi.org/10.1002/smj.683

Dutta, S., Narasimhan, O., \& Rajiv, S. (1999). Success in high-technology markets: Is marketing capability critical? Marketing science, 18(4), 547-568. doi:https://doi.org/10.1287/mksc.18.4.547

Eidizadeh, R., Salehzadeh, R., \& Esfahani, A. C. (2017). Analysing the role of business intelligence, knowledge sharing and organisational innovation on gaining competitive advantage. Journal of Workplace Learning, 29(4), 250-267. doi:https://doi.org/10.1108/JWL-07-2016-0070

Fornell, C., \& Larcker, D. F. (1981). Evaluating structural equation models with unobservable variables and measurement error. Journal of marketing research, 18(1), 39-50. doi:https://doi.org/10.1177/002224378101800104

Hair, J. F., Risher, J. J., Sarstedt, M., \& Ringle, C. M. (2019). When to use and how to report the results of PLS-SEM. European business review, 31(1), 2-24. doi:https://doi.org/10.1108/EBR-11-2018-0203

Hair Jr, J. F., Hult, G. T. M., Ringle, C. M., \& Sarstedt, M. (2021). A primer on partial least squares structural equation modeling (PLS-SEM): Sage publications.

Hair Jr, J. F., \& Lukas, B. (2014). Marketing research (vol. 2). In: McGraw-Hill Education Australia.

Hoopes, D. G., \& Postrel, S. (1999). Shared knowledge,"glitches," and product development performance. Strategic Management Journal, 20(9), 837-865. doi:https://doi.org/10.1002/(SICI)1097-0266(199909)20:9<837::AIDSMJ54>3.0.CO;2-I

Howell, K. E., \& Annansingh, F. (2013). Knowledge generation and sharing in UK universities: a tale of two cultures? International journal of information management, 33(1), 32-39. doi:https://doi.org/10.1016/j.ijinfomgt.2012.05.003

Huber, G. P. (1996). Organizational learning: a guide for executives in technology-critical organizations. International Journal of Technology Management, 11(7), 821-832.

Johnson, J. L., \& Sohi, R. S. (2001). The influence of firm predispositions on interfirm relationship formation in business markets. International Journal of Research in Marketing, 18(4), 299-318. doi:https://doi.org/10.1016/S0167-8116(01)00042-8

Jyoti, J., Kotwal, S., \& Rani, R. (2015). Impact of knowledge management practices on competitive advantage: empirical experiences from telecommunication sector in India. In Investigating Cultural Aspects in Indian Organizations (pp. 111-128): Springer.

Koza, M., \& Lewin, A. (2000). Managing partnerships and strategic alliances: raising the odds of success. European Management Journal, 18(2), 146-151. doi:https://doi.org/10.1016/S0263-2373(99)00086-9

Lei, D. (1993). Offensive and defensive uses of alliances. Long Range Planning, 26(4), 3241. doi:https://doi.org/10.1016/0024-6301(93)90055-K

Lin, M. J. J., \& Chen, C. J. (2008). Integration and knowledge sharing: transforming to long-term competitive advantage. International Journal of Organizational Analysis, 16(1), 83-108. doi:https://doi.org/10.1108/19348830810915514

Magnier-Watanabe, R., \& Senoo, D. (2009). Congruent knowledge management behaviors as discriminate sources of competitive advantage. Journal of Workplace Learning, 21(2), 109-124. doi: https://doi.org/10.1108/13665620910934816

Naylor, M. W., King, C. A., Kathleen, A., Lindsay, B., EVANS, T., ARMELAGOS, J., . . . GREDEN, J. F. (1993). Sleep deprivation in depressed adolescents and psychiatric controls. Journal of the American Academy of Child \& Adolescent Psychiatry, 32(4), 753-759. 
O'Reilly III, C. A., \& Tushman, M. L. (2011). Organizational ambidexterity in action: How managers explore and exploit. California management review, 53(4), 5-22. doi:https://doi.org/10.1525/cmr.2011.53.4.5

O'Shannassy, T. F. (2016). Strategic intent: The literature, the construct and its role in predicting organization performance. Journal of Management \& Organization, 22(5), 583-598. doi:https://doi.org/10.1017/jmo.2015.46

Ramoniene, L., \& Lanskoronskis, M. (2011). Reflection of higher education aspects in the conception of national competitiveness. Baltic Journal of Management, 6(1), 124139. doi:https://doi.org/10.1108/17465261111100932

Reid, F. (2003). Creating a knowledge-sharing culture among diverse business units. Employment Relations Today, 30(3), 43-49.

Rowley, J. (2000). Is higher education ready for knowledge management? International Journal of Educational Management, 14(7), 325-333. doi:https://doi.org/10.1108/09513540010378978

Seepana, C., Paulraj, A., \& Huq, F. A. (2020). The architecture of coopetition: Strategic intent, ambidextrous managers, and knowledge sharing. Industrial Marketing Management, 91, 100-113. doi:https://doi.org/10.1016/j.indmarman.2020.08.012

Simonin, B. L. (2004). An empirical investigation of the process of knowledge transfer in international strategic alliances. Journal of international business studies, 35(5), 407-427. doi:https://doi.org/10.1057/palgrave.jibs.8400091

Soekijad, M., \& Andriessen, E. (2003). Conditions for knowledge sharing in competitive alliances. European Management Journal, 21(5), 578-587. doi:https://doi.org/10.1016/S0263-2373(03)00107-5

Trow, M. A. (2005). An American perspective on British higher education: the decline of diversity, autonomy and trust in post-war British higher education.

UNESCO, E. F. (2004). Global Monitoring Report 2003/4.

Wetzels, M., Odekerken-Schröder, G., \& Van Oppen, C. (2009). Using PLS path modeling for assessing hierarchical construct models: Guidelines and empirical illustration. MIS quarterly, 33(1), 177-195. doi:https://doi.org/10.2307/20650284

$\mathrm{Wu}$, J., \& Chen, X. (2012). Leaders' social ties, knowledge acquisition capability and firm competitive advantage. Asia Pacific Journal of Management, 29(2), 331-350. doi:https://doi.org/10.1007/s10490-011-9278-0 